\title{
INVESTIGACIÓN
}

Recibido: 29/03/2021 --- Aceptado: 12/05/2021 --- Publicado: 07/06/2021

\section{INSTAGRAM COMO DISPOSITIVO DE NORMALIZACIÓN DE REPRESENTACIONES IDENTITARIAS DESOBEDIENTES. ESTUDIO DE CASO}

\author{
Instagram as a device for the normalization of disobedient identity \\ representations. A case study
}

\begin{abstract}
$\mathbb{R}^{6}$ Lorena Arévalo Iglesias ${ }^{1}$ CESUGA-Universidad San Jorge. España. larevalo@usj.es
\end{abstract}

Rut Martínez López de Castro². Universidad de Vigo. España. rut@uvigo.es

Investigación realizada con el apoyo de la Cátedra de Feminismos 4.0 de la Universidad de Vigo y la Diputación de Pontevedra.

\section{Cómo citar el artículo:}

Arévalo Iglesias, L. y Martínez López de Castro, R. (2021). Instagram como dispositivo de normalización de representaciones identitarias desobedientes. Estudio de caso. Vivat Academia. Revista de Comunicación, 154, 47-62. http:/ / doi.org/10.15178/va.2021.154.e1363 http://www.vivatacademia.net/index.php/vivat/article/view/1363

\section{RESUMEN}

Las redes sociales constituyen una herramienta de difusión, construcción y encuentro de gran utilidad para los movimientos sociales y colectivos, también en el ámbito feminista/queer. Sin embargo, algunas/os autoras/es consideran que su papel decisivo en los procesos de socialización de género de las nuevas generaciones no siempre es positivo, pues replica, en buena medida, aquellos estereotipos de género que limitan y coartan la libre expresión identitaria. Bajo esa premisa, el presente trabajo se propone describir y analizar las representaciones de género presentes en las fotografías de Instagram vinculadas a cuatro campus universitarios gallegos (un total

\footnotetext{
${ }^{1}$ Lorena Arévalo Iglesias: Doctora en Comunicación por la UVigo. Profesora titular del grado de Publicidad y RRPP, Escuela de Comunicación y Ciencias Sociales de CESUGA-Universidad San Jorge. Miembro del Grupo de investigación en Diseño sostenible.

${ }^{2}$ Rut Martínez López de Castro: Doctora en Arte y Educación por la UB. Profesora asociada del Departamento de Didácticas Especiales, Facultad de Ciencias de la Educación y del Deporte de la UVigo. Miembro del Grupo de investigación en Educación, actividad física y salud (GIES10).
} 
Arévalo Iglesias, L., y Martínez López de Castro, R.

Instagram como dispositivo de normalización de representaciones identitarias desobedientes. Estudio de caso

de 449 imágenes), mediante un análisis de contenido complementado por un análisis descriptivo univariable y bivariable, con tablas de contingencia, residuos tipificados y test Ji-cuadrado de Pearson. Dicho análisis atiende a criterios objetivos, vinculados con las realidades perceptibles de los cuerpos representados. Como resultado, se ha observado una fuerte tendencia a las representaciones normativas, con una baja presencia de identidades de género "desobedientes" que operen como un laboratorio de exploración y búsqueda de nuevas corporeidades/identidades. Se concluye, por tanto, que Instagram funciona como una herramienta de legitimación de la propuesta binaria, normativa y, por lo tanto, hegemónica. Así, el estudio permite identificar las estrategias de construcción de las identidades de género online que manifiesta la juventud universitaria en estos cuatro campus gallegos.

PALABRAS CLAVE: Instagram - Fotografías - Feminismo - Queer - Socialización de género - Identidades desobedientes - Representación heteronormativa - Juventud Exposición.

\section{ABSTRACT}

Social media are a very useful dissemination, construction and meeting tool for social and collective movements, also in the feminist/queer sphere. However, some authors consider that their decisive role in the gender socialization processes of the new generations is not always positive, as it replicates, to a large extent, those gender stereotypes that limit and restrict free identity expression. Under this premise, the present work aims to describe and analyze the gender representations observable in Instagram photographies linked to four Galician university campuses (a total of 449 images), through a content analysis complemented by a univariate and bivariate descriptive analysis, with contingency tables, standardized residuals and Pearson's Chi-square test. This analysis attends to objective criteria, linked to the perceptible realities of the represented bodies, and allows us to identify the strategies for the construction of online gender identities manifested by university youth in those four Galician campuses. This way, no "disobedient" gender identities have been found that operate as a laboratory for the exploration and search for new corporeities/identities, which is why we can observe a strong tendency towards normative representations. It is thus concluded that Instagram works as a legitimation tool for the binary, normative and, therefore, hegemonic proposal.

KEYWORDS: Instagram - Photographs - Feminism - Queer - Gender socialization Disobedient identities - Heteronormative representation - Youth - Exhibition.

\section{INSTAGRAM COMO DISPOSITIVO DE NORMALIZAÇÃO DE REPRESENTAÇÕES IDENTITÁRIAS DESOBEDIENTES. ESTUDO DE CASO}

Vivat Academia. Revista de Comunicación. 2021, nº 154, 47-62 
Arévalo Iglesias, L., y Martínez López de Castro, R.

Instagram como dispositivo de normalización de representaciones identitarias desobedientes.

\section{Estudio de caso}

\section{RESUMO}

As redes sociais constitui uma ferramenta de difusao, construção e encontro de grande utilidade para os movimentos sociais e coletivos, tambem para o âmbito feminista/queer. Porém algumas/os autoras/es consideram que seu papel decisivo nos processos de socialização de gênero das novas gerações nem sempre é positivo, pois replica, em boa medida, naqueles estereótipos de gênero que limitam e restringem a livre expressão identitária. Sob esta premissa, o presente trabalho se propõe descrever e analisar as representações de gênero presentes nas fotografias de instagram vinculadas a quatro campus universitários da cidade de Galicia (um total de 449 imagens), mediante uma análise de conteúdo complementado por uma análise descritiva univariável e bivariável, com tabelas de contingência, resíduo e contingência, resíduos tipificados e test de Chi-quadrado de Pearson. Esta análise atende critérios objetivos, vinculados às realidades perceptíveis dos corpos representados. Como resultado tem se observado uma forte tendência das representações normativas, com uma baixa presença de identidades de gênero desobedientes" que funcionam como um laboratório de exploração e pesquisa de novas corporeidades/identidades. Se conclui então, que o Instagram funciona como uma ferramenta de legitimação da proposta binária, normativa e, portanto, hegemónica. Assim, este estudo permite identificar as estratégias de construção de identidades de gênero online que manifesta a juventude universitária nestes quatro campus da cidade de Galicia.

PALAVRAS CHAVE: Instagram - Fotografías - Feminismo - Queer - Socializaçâo de gênero - Identidades desobedientes - Representação heteronormativa - Juventude Exposição

\section{INTRODUCCIÓN}

Tanto el feminismo como el activismo queer encuentran hoy en los medios sociales de naturaleza virtual una potente herramienta de difusión. Además de contribuir a la divulgación del pensamiento feminista y al reconocimiento y expansión de las bases de la teoría queer, las redes sociales permiten que activistas vinculadas/os con estos movimientos (así como personas con sensibilidades afines a estos temas) se encuentren, refuercen y empoderen en estos espacios virtuales, influyendo en la socialización de género de las nuevas generaciones (Blanco Ruiz, 2014, p. 1) y permeando "la totalidad de la estructura social, modificando la vida cotidiana" (Aránguez Sánchez, 2019, p. 255).

Las redes sociales constituyen un medio de comunicación, un elemento mediador más en el entorno cultural (Sánchez-Labella Martín \& Romo-Parra, 2021, p. 81), capaz de despertar el interés tanto de movimientos sociales como el feminismo, como de aquellos sectores de la sociedad afines a ellos. Así, en los últimos años el empleo de las redes sociales en el ámbito del activismo feminista y queer se ha popularizado, demostrando ser una herramienta útil (Sádaba \& Barranquero, 2019, p. 3) para la conceptualización y ejecución de nuevas formas de denuncia y protesta, creando

Vivat Academia. Revista de Comunicación. 2021, nº 154, 47-62 
espacios de construcción colectiva para aquellas generaciones socializadas en el entorno offline, hasta tal punto que "el feminismo ha invadido la esfera pública con claridad a través de la Red" (Sell-Trujillo, Núñez Domínguez \& Aix-Gracia, 2021, p. 147). Sin embargo, las redes sociales presentan claras limitaciones en lo referente a las generaciones más jóvenes ajenas a estos movimientos, cuya socialización de género se $\mathrm{da}$, sobre todo, en el terreno virtual. En un contexto (el de las redes sociales) en el que la misoginia continúa siendo hegemónica (Albenga \& Biscarrat, 2021, p. 59), la limitación más perniciosa implica que, mientras el empleo de estas redes "potencia la sensación de comunidad y la democratización de la divulgación y visibilidad de sujetos feministas más diversos" (Sánchez Duarte \& Fernández Romero, 2017, p. 900), el mensaje subyacente parece clamar por el empoderamiento de las/os sujetos a nivel individual frente al colectivo, desde un enfoque limitado y carente de un discurso crítico real (Caro Castaño, 2015, p. 127).

Se da entonces entre las/os usuarias/os de estas plataformas una falsa sensación de unidad y fuerza colectiva, sostenida sobre un sentimiento de pertenencia que oculta la realidad de la atomización del grupo en un contexto de "colectividades ligeras" (Zafra, 2010, p. 74). Así, la socialización en el género realizada en el aparente marco del colectivo, cuando en realidad se está llevando a cabo de forma individual y aislada, acaba por condicionar dicho proceso de socialización. Ese "hacer género para mostrar el género como un proceso individual" (West \& Zimmerman, 1987, p. 126) se ve supeditado a los valores y prácticas culturales que definen cómo deben comportarse hombres y mujeres, de acuerdo a las expectativas de cada sociedad (Wood, 2009, p. 20).

Esa construcción individualizada tiene reflejo, a su vez, en la representación de las identidades de género por parte de la juventud en redes sociales, dando lugar a una espiral representación/construcción/representación que se retroalimenta. Así, cuando la representación de las identidades subjetivas pretende responder a expectativas externas, prima una expresión de género, como se ha dicho, simplista y acrítica. Se corre entonces el riesgo de "replicar las versiones normativas culturales y de los medios de comunicación, específicamente en lo que se refiere al género" (Rettberg, 2009, p. 453). En lo relativo a la representación de las subjetividades en redes sociales, estos factores dificultan la reivindicación de identidades de género desobedientes entre la juventud, limitando la presencia de expresiones de género alternativas en aquellas plataformas en las que la imagen constituye el pilar central de la comunicación, como es el caso de Instagram.

Pero las expectativas sociales, reforzadas por la ausencia de modelos de construcción de las identidades que puedan servir como elementos de contraste (favorecidas, a su vez, por esta suerte de "socialización individual"), no son el único elemento que influye en la construcción de representaciones de género hegemónicas. La falta de libertad a la hora de desarrollar representaciones del género más libres se ve también reforzada tanto por el carácter comercial de dichas plataformas, como por los sistemas de algoritmos que estas emplean (Caro Castaño, 2015, p. 127-128), pues 
castigan las representaciones desobedientes condenándolas a la invisibilidad o, directamente, censurándolas y eliminándolas de sus espacios.

En el ámbito académico, Dall'Orso-Swayne y Arbaiza (2021, p. 128) indican que las/os autoras/es que han tratado este tema se dividen entre quienes consideran que Internet favorece el sesgo informativo (lo que lleva a las/os usuarias/os a reforzar sus opiniones), y quienes sostienen que la Red expone a esas/os usuarias/os a contenidos, opiniones y argumentos a los que no podrían tener acceso de otra forma. Así, si bien algunas/os autoras/es sostienen que "la socialización de género en Internet está convirtiéndose en una nueva forma de socialización basada en una definición moderna de género que gira alrededor de los conceptos de fluidez, construcción y actuación" (Dueñas et al., 2016, p. 69), existen voces críticas que sostienen que las representaciones de género presentes en las redes sociales responden a estereotipos presentes en medios de comunicación tradicionales del ámbito offline (Rose et al., 2012, p. 604): es decir, las mismas expresiones hegemónicas condicionadas por la sociedad, de acuerdo con un determinado imaginario de género. El imaginario de género ha sido conceptualizado como un constructo complejo y sistémico, producto y productor de actividades conversacionales, construidas social e históricamente, que abordan el hecho de ser hombre/mujer ( $u$ otra identidad no dicotómica). Este imaginario se manifiesta en elementos específicos interrelacionados entre sí y que están presentes en imágenes culturales: asignación sexual, identidad de género, orientación sexual, vestimenta, rol adoptado, tipo de protagonismo en la acción, expresión, etc.

Por ello, el análisis de las fotografías en los perfiles de Instagram permite identificar las estrategias para la construcción de identidades de género online expresadas por las/os jóvenes, agregando la distinción según los espacios físicos en los que se desarrolla la vida retratada y trazando paralelismos entre espacios físicos/virtuales diferenciados, ya que cada lugar presenta ciertas reglas y el comportamiento de las personas cambia según el lugar donde se encuentre (Cortés \& Itarte, 2013, p. 78).

\section{OBJETIVOS}

El presente trabajo de investigación se propone abordar el papel de Instagram en los procesos de reproducción de representaciones identitarias hegemónicas/desobedientes desde un enfoque de género, partiendo de un estudio de caso. Recoge, así, los resultados de los proyectos de investigación "Instagram: imaginarios de género de la juventud", realizado con el apoyo de la Cátedra Feminista de la Universidad de Vigo. Dicho proyecto constó de dos fases: "A Xunqueira de Pontevedra" (desarrollada en 2019) y "Estudio comparativo entre espacios virtuales de los campus gallegos" (desarrollada en 2020). La primera fase se centró en los imaginarios de género que se representan en fotografías de Instagram vinculadas a espacios virtuales desarrollados por los universitarios alrededor del campus A Xunqueira de Pontevedra (Universidad de Vigo). La segunda fase estableció una comparativa entre el imaginario vinculado al campus de la Universidad de Vigo en la capital, y los imaginarios vinculados a los campus principales de otras universidades públicas gallegas.

Vivat Academia. Revista de Comunicación. 2021, nº 154, 47-62 
Arévalo Iglesias, L., y Martínez López de Castro, R.

Instagram como dispositivo de normalización de representaciones identitarias desobedientes. Estudio de caso

\section{METODOLOGÍA}

Para el desarrollo de la presente investigación se emplearon dos metodologías de análisis complementarias (cuantitativa y cualitativa). Por un lado, se realizó una investigación empírica descriptiva de análisis primario durante la cual se analizaron, mediante un sistema de categorías, las fotografías que configuran los espacios virtuales de los campus de A Xunqueira (UVigo, Pontevedra), Campus Noste y Sur o Vida (USC, Santiago de Compostela) y Campus de Elviña (UDC, A Coruña). Por otro, y de manera complementaria, se realizó un análisis de contenido de las mismas imágenes, lo que permitió identificar pequeños matices o aspectos relevantes que el análisis cuantitativo, por su naturaleza, dejaba fuera. La muestra está formada por un total de 449 imágenes compartidas en Instagram entre el 1 de mayo y el 30 de junio de 2019, vinculadas (ya sea por ubicación, por el hashtag utilizado o por el nombre con el que las/os usuarias/os de Instagram etiquetaron las imágenes) con una serie de facultades pertenecientes a los Campus Norte y Campus Sur o Vida (Universidade de Santiago de Compostela, USC), Campus Crea/A Xunqueira (Universidade de Vigo, UVigo) y Campus de Elviña (Universidade de A Coruña, UDC).

Para analizar las representaciones identitarias de género de la juventud universitaria gallega en Instagram se diseñó una ficha de observación mediante un sistema de categorías adoptadas del modelo de Táboas-Pais (2009) a los que se le añadieron indicadores creados ad hoc. Así, la ficha de observación se dividió en tres dimensiones con 9 variables dependientes e independientes: Dimensión 1. El Cuerpo; Dimensión 2. Mensaje. Las variables dependientes consideradas son: orientación sexual, protagonismo, rol, vestimenta, cobertura corporal, expresión. Como variables independientes se tuvieron en cuenta agrupación por sexo, edad y orientación sexual. La ficha de observación utilizada para este proyecto está compuesta por 56 categorías correspondientes a variables dependientes e independientes.

Todas las variables presentadas en este estudio son nominales atributivas y cualitativas con la excepción de la variable edad que es ordinal. Para facilitar el proceso de codificación, se ha asignado una etiqueta numérica a cada variable para reemplazar el nombre de la categoría o el indicador.

El estudio incorpora el análisis de elementos visuales vinculados a la afiliación y/o identificación de los jóvenes retratadas/os, como una categoría que busca identificar y clasificar a todos aquellas insignias visuales presentes en la imagen que vinculan a la persona o personas que figuran en ella con algún tipo de grupo, institución, empresa, ideología, etc. La inclusión de esta categoría se entiende necesaria para enriquecer el análisis sobre la identidad de las/os jóvenes retratadas/os, como evidencia de su deseo de pertenencia.

El análisis de datos realizado consistió en un análisis descriptivo univariable y bivariable. Se utilizarán tablas de contingencia, residuos tipificados corregidos y la

Vivat Academia. Revista de Comunicación. 2021, nº 154, 47-62 
Arévalo Iglesias, L., y Martínez López de Castro, R.

Instagram como dispositivo de normalización de representaciones identitarias desobedientes.

\section{Estudio de caso}

prueba de Ji-cuadrado de Pearson $-\chi 2$ - con un nivel de significancia de 5\% $-\alpha=.05-$. Para ello, como en la primera fase, se utilizó el paquete estadístico SPSS 20.

Para la realización de este estudio se siguió este proceso:

1. Comienzo del proyecto en el año 2019 sobre los imaginarios de género presentes en las fotografías de Instagram de las/os universitarias/os relacionadas con los espacios virtuales de la Xunqueira de Pontevedra.

2. Continuación del estudio en el año 2020, ampliando la perspectiva de análisis y el ámbito de actuación. Se determina como objetivo realizar una comparativa entre las imágenes virtuales de los universitarios gallegos desde una perspectiva de género.

3. Realización de la observación y análisis de contenido de las imágenes de Instagram de las/os universitarias/os gallegas/os durante los meses de mayo y junio de 2019.

\section{RESULTADOS}

\subsection{Dimensión cuerpo}

\subsubsection{Sexo-agrupación y Edad}

La categoría Sexo es entendida como las diferencias biológicas y naturales entre hombres y mujeres. En la UVigo está representada con imágenes predominantes de grupos mixtos de hombres y mujeres (56\%). Por otra parte, se han registrado más fotografías de grupos de hombres $(15 \%)$ y de hombres solos $(12 \%)$ que de grupos de mujeres (5\%) y de mujeres solas (11\%). Esta mayor presencia de hombres en el Campus de A Xunqueira se explica por la fuerte vinculación del campus con el campo deportivo.

Las imágenes relacionadas con la UDC, coincide con las imágenes de UVigo en la preeminencia de fotografías de grupos mixtos de hombres y mujeres (43\%). Le siguen en menor porcentaje, las imágenes de grupos de mujeres $(26 \%)$ y de mujeres solas $(19 \%)$, frente a un $5 \%$ de imágenes relativas a grupos de hombres y un $4 \%$ de imágenes de hombres solos.

En el caso de la USC, los grupos de hombres es la representación más frecuente $(45 \%)$. También tiene una presencia importante, pero menor, las imágenes de mujeres solas (35\%). Sin embargo, las imágenes de hombres solos (15\%) y de grupos de mujeres (3\%) tienen baja presencia.

En cuanto a la Edad, las tres universidades presentan resultados similares. La mayoría de imágenes corresponden a personas jóvenes que se encuentran aparentemente entre 19 y 35 años de edad. En la UVigo, las imágenes de personas jóvenes suponen el $58 \%$. La UDC tiene el porcentaje de personas jóvenes más alto de las tres universidades, con un 79\%. En la USC representan el 51\%. 
Arévalo Iglesias, L., y Martínez López de Castro, R.

Instagram como dispositivo de normalización de representaciones identitarias desobedientes. Estudio de caso

En segundo lugar se encuentran las imágenes en las que el protagonismo es compartido por personas de edades diferentes. En la UVigo se corresponde con el 30\%; en la UDC un $20 \%$; y en la USC, un $32 \%$.

Asimismo, hay una mínima presencia de personas adultas cuya apariencia indica una edad comprendida entre los 36 y los 65 años. Por universidades, la UDC contiene el porcentaje más alto de imágenes con personas adultas con un 14\%, le sigue la UVigo con un $6 \%$, y sin embargo en la UDC no se han observado imágenes con personas de edad adulta. También, las imágenes de niñas/os y adolescentes con una edad aparente comprendida entre 0 y 18 años tienen una baja presencia. En la UVigo encontramos un $4 \%$ de imágenes de niñas/os y adolescentes, y tanto en la UDC como la USC no aparecen representadas.

\subsubsection{Protagonismo y rol}

Es posible observar en las imágenes de la UVigo un protagonismo mixto de hombres y mujeres en un $46 \%$ de la muestra. El 35\% de las imágenes corresponde a un protagonismo masculino, y un $18 \%$ al femenino.

En el caso de las imágenes analizadas relacionadas con la UDC y la USC hay una mayor frecuencia de protagonismo femenino. Las imágenes de mujeres solas mantienen un porcentaje alto en la UDC (con un 47\%) y en la USC (con un 40\%). Asimismo, el porcentaje de imágenes con protagonismo mixto es bastante similar al de las imágenes con protagonismo femenino, con un $40 \%$ en la UDC y un $39 \%$ en la USC.

Así, se puede observar que las mujeres solo son protagonistas cuando están "solas" (sin presencia masculina) en las fotografías. En los casos en que las imágenes registran grupos de hombres y mujeres, ocurre lo siguiente: el protagonismo suele ser mixto, aunque existen algunas imágenes en las que los hombres son los protagonistas; mientras tanto, las mujeres nunca son protagonistas cuando hay hombres presentes.

El rol desempeñado por las personas fotografiadas es mayoritariamente pasivo, dado que no llevan a cabo ninguna acción concreta o no son fuente directa de acción por estar sometidas a iniciativas de otras personas.

En la UVigo las imágenes con personas pasivas corresponden a un $63 \%$, frente a un $25 \%$ de imágenes con personas en posición activa que realizan alguna acción o son sujetos de acción. En la UDC el porcentaje de imágenes con personas "pasivas" es alto, llegando a un $94 \%$ frente a un $6 \%$ de representaciones en acción. En la USC, un 72\% de los/as retratados/as aparecen en posición pasiva frente a un $25 \%$ en posición activa.

A través del análisis de contingencia de la variable sexo-agrupación y rol se ha obtenido estos resultados. En la UVigo los hombres solos y en grupo aparecen en posición pasiva en un $41 \%$ frente a las mujeres solas y en grupo con un $26 \%$. En posición activa, nuevamente son los hombres los que lideran el porcentaje. Se observan

Vivat Academia. Revista de Comunicación. 2021, nº 154, 47-62 
Arévalo Iglesias, L., y Martínez López de Castro, R.

Instagram como dispositivo de normalización de representaciones identitarias desobedientes. Estudio de caso

9 casos (37\%) de la muestra de hombres solos y en grupo en posición activa, frente a 6 casos $(25 \%)$ donde las mujeres solas y en grupo mantienen una posición activa.

En la UDC las mujeres solas y en grupo son las que ostentan tanto las actitudes pasivas (con un $47 \%$ ) como las activas (con un 50\%). Los hombres solos y en grupo mantienen una representación de un $10 \%$ en rol pasivo y un $0 \%$ en rol activo. Contrariamente a la UDC, las imágenes asociadas a la USC proporcionan una muestra mayoritaria de un $72 \%$ de hombres solos y en grupo con un rol activo frente a un $27 \%$ de mujeres con este rol. El rol pasivo tiene menor relevancia en las imágenes con figuras masculinas (55\%), sin embargo, mantienen un porcentaje importante en el caso de las figuras femeninas (44\%).

\subsubsection{Indumentaria y cobertura del cuerpo}

La indumentaria denominada ropa urbana/casual se define como una vestimenta informal y desenfada, a veces experimental, propia del día a día, en lo que prima la comodidad. Este tipo de indumentaria es predominante en las imágenes de las personas fotografiadas en la UVigo y de la USC. En la UVigo, las personas que aparecen en las imágenes utilizan en un 32\% ropa urbana/casual, le sigue en porcentaje las personas con ropa de fiesta $(26 \%)$, y en menor medida, la indumentaria de ropa formal $(13 \%)$, de uniforme $(10 \%)$ o de otro tipo $(11 \%)$.

La presencia de ropa uniformada en la UVigo está asociada a la existencia de la Facultad de Ciencias de la Educación y el Deporte y la Facultad de Fisioterapia. En ambas facultades es común la utilización de prendas de deporte uniformadas y vestuario de trabajo para la salud.

En las imágenes de UDC, la mayoría de las personas fotografiadas (78\%) lucen una indumentaria formal, entendiendo como tal una vestimenta de estilo conservador y serio, asociado generalmente a contextos laborales y académicos. En menor porcentaje, se observa que un $17 \%$ de los casos las/os personas fotografiadas presentan un estilo urban, un $3 \%$ con uniforme y un $1 \%$ con otro tipo de ropa.

En las fotografías de la USC, la indumentaria más frecuente es la urban o casual $(60 \%)$, y solamente encontramos un $24 \%$ de personas que llevan vestidos de fiesta, y un $6 \%$ de personas uniformadas.

En cuanto al análisis de contingencia de sexo e indumentaria, la muestra proporciona estos resultados por universidades. En la UVigo, tanto mujeres como hombres llevan mayoritariamente ropa urban (40\%). Además, los hombres solos o en grupo además de llevar ropa urban, aparecen en un $24 \%$ con ropa formal y en un $14 \%$ con ropa deportiva. Y las mujeres fotografiadas visten en un $20 \%$ con ropa de deporte y en un $10 \%$ con ropa de fiesta.

En la UDC los hombres y mujeres solos y en grupo llevan mayoritariamente ropa formal, los hombres en un $32 \%$ y las mujeres en un porcentaje de un 18\%. En menor

Vivat Academia. Revista de Comunicación. 2021, nº 154, 47-62 
Arévalo Iglesias, L., y Martínez López de Castro, R.

Instagram como dispositivo de normalización de representaciones identitarias desobedientes.

\section{Estudio de caso}

proporción los hombres llevan ropa uniformada (14\%) y casual (7\%), y las mujeres, ropa urban $(16 \%)$ y de uniforme $(6 \%)$.

En la USC, el 40\% de los hombres fotografiados solos o en grupo llevan ropa urban, un $13 \%$ ropa de fiesta, y un $4 \%$ ropa formal. Las mujeres solas o en grupo utilizan mayoritariamente ropa urban $(18 \%)$, ropa de fiesta en un $12 \%$, en menor porcentaje ropa formal $(1 \%)$.

En cuanto a la cobertura del cuerpo, se ha analizado el grado de cobertura del cuerpo. En las imágenes asociadas a las tres universidades, las personas fotografiadas llevan ropa cotidiana dejando al descubierto solamente parte de los brazos, tronco o piernas. En la UVigo, corresponde al 100\% de las imágenes, en la UDC en el $98 \%$ y en la USC en el $91 \%$.

Otro grado de cobertura corporal se percibe en las imágenes de la UDC y la USC. En ellas es posible encontrar personas o grupos de personas que llevan prendas de vestir cortas identificadas como cobertura del cuerpo sugerente. En el caso de la UDC se distingue un porcentaje de un $1 \%$ asociado a grupos grupos de hombres y mujeres. En la USC el porcentaje de cobertura corporal sugerente corresponde a un $9 \%$, de los cuales, 11 casos son mujeres solas o en grupo, y 6 casos son hombres solos o en grupo.

\subsection{Dimensión mensaje}

\subsubsection{Expresión}

Se ha observado que la expresión de satisfacción es la que representa a la mayoría de las personas fotografiadas, presente con varios o algunos de esos indicativos como: sonrisa pronunciada, cuerpo y cabeza erguida, pecho abierto, mirada firme. Estos signos indican una situación de bienestar, gozo y felicidad.

Las personas vinculadas a la UVigo aparecen mayoritariamente con expresión de satisfacción en un $46 \%$ de los casos. Otras expresiones menos representadas son la concentración con un $20 \%$, la vigorosidad con un $3 \%$, la socialización con un $3 \%$, la transgresión con un $2 \%$, la seducción y la autoridad, ambas con un $1 \%$.

El protagonismo de la expresión de concentración en el Campus de A Xunqueira va a estar menos presente en los otros dos campus. Esto se puede explicar por las imágenes registradas durante el transcurso de las actividades prácticas en el marco de los procesos formativos. Es decir, tiempos en los que los estudiantes desarrollan tareas de las que se esperan resultados específicos, como las prácticas del alumnado de Fisioterapia, que trabaja sobre cuerpos reales.

Sin embargo, lo más destacable del análisis de la expresión de las personas fotografiadas en la UVigo, sobre todo si se compara con las imágenes grabadas en la UDC y la USC, es el hecho de que no exista una imagen que identifique un gesto que indique complicidad entre las personas fotografiadas.

Vivat Academia. Revista de Comunicación. 2021, n 154, 47-62 
Arévalo Iglesias, L., y Martínez López de Castro, R.

Instagram como dispositivo de normalización de representaciones identitarias desobedientes. Estudio de caso

En la UDC, la expresión de complicidad (46\%) es la más usual en las personas fotografiadas. Esta expresión se identifica con estas características siguientes: miradas cruzadas, cuerpo orientado cara a la otra persona, contacto físico entre ellas o sonrisa. Es decir, una actitud o relación de cooperación o simpatía entre ellas.

Otras expresiones observadas en las personas de la UDC, es la satisfacción en un $30 \%$, la serenidad o tranquilidad en un 10\%, la seducción un $2 \%$, la socialización un $2 \%$ y la vigorosidad en un $1 \%$.

En la USC, al igual que en la UVigo, la expresión de satisfacción (51\%) es la que aparece en un elevado número de las personas fotografiadas. Con menor incidencia aparecen gestos compatibles con concentración (8\%), seducción (6\%), complicidad $(6 \%)$, autoridad (6\%), transgresión (1\%), introspección $(1 \%)$, y otras expresiones.

Para este estudio, resulta relevante destacar la ausencia de expresiones y manifestaciones de transgresión entendiendo por esto gestualidades que indiquen intención de provocación, desobediencia y de ruptura de la expresión de la normativa de género.

En cuanto a la expresión teniendo en cuenta el sexo de las personas fotografiadas, en la UVigo se observa la expresión de satisfacción en un 50\% en hombres solos y en grupo. Entre las mujeres solas y en grupo, se encuentra en un $45 \%$ de los casos. Hay otros gestos y expresiones diferenciadas en los hombres, como la concentración (20\%), la vigorosidad (10\%), la socialización (5\%), y la autoridad (5\%). En las imágenes de mujeres se percibe miradas y gestos orientados a la concentración (45\%) y la satisfacción (45\%), y en menor porcentaje la expresión de seguridad (9\%).

En las imágenes de la UDC, los hombres solos o en grupo tienen mayoritariamente expresión de satisfacción (31\%) y de serenidad (31\%), y con menor incidencia de complicidad (25\%) y de concentración (6\%). Las expresiones que se observan en las mujeres son de complicidad (45\%), de satisfacción (37\%), y en menor porcentaje, la expresión de serenidad (12\%), seducción (1\%), introspección $(1 \%)$ y concentración $(1 \%)$.

Los hombres y mujeres fotografiadas/os asociadas/os con la USC tienen como expresión predominante la satisfacción, los hombres en un porcentaje de un $50 \%$, y las mujeres en un porcentaje de un $47 \%$. Además, existen varios gestos y expresiones en los hombres que sugieren intencionalidad de concentración (13\%), socialización (8\%), transgresión (1\%) y seducción (1\%). Los gestos y miradas de las mujeres de la USC están más enfocadas a la complicidad (15\%), la introspección (4\%), la serenidad (4\%) y la socialización $(4 \%)$.

En el caso de este campus de la USC, llama la atención la expresión de complicidad. Si bien es una expresión que se repite en las imágenes analizadas, no hay un solo caso 
Arévalo Iglesias, L., y Martínez López de Castro, R.

Instagram como dispositivo de normalización de representaciones identitarias desobedientes. Estudio de caso

de complicidad entre hombres, y solo un caso de complicidad entre hombres y mujeres. Los casos restantes corresponden a muestras de complicidad entre mujeres.

\section{DISCUSIÓN Y CONCLUSIONES}

Es preciso comenzar este apartado destinado a las conclusiones del estudio haciendo referencia a una de las limitaciones del mismo, pues, a la luz de los datos obtenidos, es posible intuir que la muestra empleada adolece de un cierto grado de sesgo de selección, que limita las posibilidades de generalización de las conclusiones obtenidas. Así, si bien ofrece una fotografía precisa de la realidad encontrada en los perfiles vinculados a los campus universitarios gallegos, difícilmente estos resultados serán extrapolables a otros sectores de la sociedad.

En líneas generales, se observa que la mayoría de las imágenes compartidas en la red social durante los meses seleccionados se limitan a documentar acontecimientos celebrados en el marco de la actividad universitaria (dadas las fechas, abundan las imágenes que registran los distintos actos de graduación que tuvieron lugar en las facultades). Así, incluso las imágenes grupales en las que se registran fiestas posteriores a los actos académicos resultan un tanto impersonales, pues apenas se pueden encontrar evidencias de gustos, actitudes, compromisos, filias o fobias. Las imágenes de estas fiestas son muy similares en los distintos campus, e incluso en las distintas facultades. Se puede hablar, por tanto, de una cierta homogeneidad narrativa.

Más allá de actitudes, consignas o evidencias de un pensamiento feminista o queer, tampoco en el ámbito del activismo político se aprecian manifestaciones evidentes. La Facultad de Geografía e Historia de la USC es la única que registra imágenes cuyas narrativas muestran un componente político importante. En la Facultad de Ciencias Sociales y de la Comunicación de la UVigo, si bien se registran actividades vinculadas con la creación y puesta en marcha de campañas de comunicación política como parte del trabajo de una asignatura, no se aprecian consignas políticas reales y extrapolables más allá de la dinámica interna del propio grupo de estudiantes.

La orientación sexual de las personas fotografiadas resulta difícilmente identificable, atendiendo a las imágenes que forman parte de la muestra. Esto hace que no resulte posible sacar conclusiones al respecto de este punto, salvo el hecho mismo de que se trata de un aspecto que no tiene visibilidad en la mayoría de las imágenes encontradas. Este hecho redunda en la idea de que, en lo que respecta a las redes sociales, muchas personas prefieren mantener determinados aspectos de su vida privada -tales como la orientación sexual- en privado, tal y como sostienen Horvát, Hanselmann, Hamprecht y Zweig (2012) en su estudio One Plus One Makes Three (for Social Networks).

Atendiendo a las imágenes analizadas, se puede concluir que los hombres adoptan una pose generalmente heteronormativa y muy masculinizada, especialmente en sus interacciones con las mujeres. Hay una relación entre géneros muy tradicional. En este sentido, la comparativa entre centros evidencia que las imágenes vinculadas a las

Vivat Academia. Revista de Comunicación. 2021, nº 154, 47-62 
Arévalo Iglesias, L., y Martínez López de Castro, R.

Instagram como dispositivo de normalización de representaciones identitarias desobedientes. Estudio de caso

facultades de comunicación de los tres campus presentan, en líneas generales, narrativas, estéticas y actitudes más libres y transgresoras que en el resto de centros.

Durante la realización del análisis no se han encontrado identidades de género "desobedientes" (manifestaciones e identidades distintas del cisgénero heteronormativo) que operen como un laboratorio de exploración y búsqueda de nuevas corporeidades/identidades. Cabe justificar este hecho debido a la fuerte institucionalización de los espacios virtuales asociados a los campus universitarios, que podría ejercer un efecto normativizador. Un efecto ya contemplado por Martínez Labrín y Bivort-Urrutia (2014, p. 17), cuando hacen referencia al "micro ambiente social que va a desarrollar relaciones de género concordantes con el binario Masculino vs. Femenino" dentro de las universidades.

Así, independientemente de los matices actitudinales presentes en las imágenes vinculadas a los tres campus analizados, en líneas generales se puede afirmar que, en lo relativo a la publicación y difusión de un imaginario de género construido por el alumnado de los campus, Instagram funciona como una herramienta de legitimación de la propuesta binaria, normativa y, por lo tanto, hegemónica, desperdiciando así su potencial disruptivo cómo medio de construcción colectiva y anónima. Este hecho podría responder al interés de las/os jóvenes/adultas/os por expresar y mostrar al mundo un yo que asumen como ideal o preferible, su mejor versión, tal y como sugieren Renau, Carbonell y Oberst (2012, p. 98). En este sentido, sería interesante completar el presente estudio con un acercamiento de corte cualitativo, centrado en la narración de las/os propias/os protagonistas, que permita a las/os usuarias/os de las redes contextualizar y definir los aspectos relacionados con la representación del self en Instagram.

En cualquier caso, se considera que esta investigación abre nuevas vías para comprender la naturaleza de la auto-representación corporal e identitaria a través de las imágenes compartidas en redes sociales. Parece relevante, por ello, plantear futuras investigaciones que permitan seguir ahondando en el estudio de la exhibición de las corporeidades de las/os jóvenes, teniendo en cuenta la posible influencia de las/os influencers en los perfiles sociales. Estudios que, como es el caso del presente, se podrían aplicar al el ámbito educativo y pedagógico.

\section{REFERENCIAS}

Albenga, V. y Biscarrat, L. (2021). Aproximaciones feministas de la misoginia en redes sociales: una perspectiva francesa. Investig. Fem (Rev.) 12 (1), 57-66.

Aránguez Sánchez, T. (2019). La metodología de la concienciación feminista en la época de las redes sociales. Ámbitos. Revista Internacional de Comunicación, 45, 238257. http://dx.doi.org/10.12795/Ambitos.2019.i45.14

Vivat Academia. Revista de Comunicación. 2021, nº 154, 47-62 
Arévalo Iglesias, L., y Martínez López de Castro, R.

Instagram como dispositivo de normalización de representaciones identitarias desobedientes. Estudio de caso

Blanco Ruiz, M. A. (2014). Implicaciones del Uso de las Redes Sociales en el Aumento de la Violencia de Género en Adolescentes. Comunicación y Medios, 30, 124-141. https://revistaschilenas.uchile.cl/handle/2250/10.5354/rcm.v0i30.32375

Caro Castaño, L. (2015). Construir y comunicar un "nosotras" feminista desde los medios sociales. una reflexión acerca del "feminismo del hashtag". Revista de Comunicación y Ciudadanía Digital COMMONS, 4 (2), 124-154. http://dx.doi.org/10.25267/COMMONS.2015.v4.i2.06

Cortés Canarelli, B. e Itarte, R. A. (2013). (Re)Construcción de identidades de género en espacios sociales y educativos. Aportaciones desde la pedagogía y la psicología. URBS. Revista de Estudios Urbanos y Ciencias Sociales, 3 (1), 69-87. http://hdl.handle.net/10835/2161

Dall'Orso-Swayne, V. y Arbaiza, F. (2021). Instagram como plataforma de ciberactivismo de influencers no-políticas a favor de movimientos feministas en Perú. RISTI E40 (01), 127-138.

Dueñas, D., Pontón, P., Belzunegui, A. y Pastor, I. (2016). Expresiones discriminatorias, jóvenes y redes sociales: la influencia del género. Comunicar, 46 (24), 67-76. https://doi.org/10.3916/C46-2016-07

Horvát, E. Á., Hanselmann, M., Hamprecht, F. A. y Zweig, K. A. (2012) Corrección: Uno más uno hace tres (para redes sociales). PLOS ONE 7 (4), 10.1371. https:// doi.org/10.1371/annotation/c2a07195-0843-4d98-a220-b1c5b77a7e1a

Martínez Labrín, S. y Bivort Urrutia, B. (2014). Procesos de producción de subjetividad de género en el trabajo académico: Tiempos y espacios desde cuerpos femeninos. Psicoperspectivas, 13 (1), 15-22. http:/ / dx.doi.org/10.5027/psicoperspectivas-Vol13$\underline{\text { Issue1-fulltext-334 }}$

Renau, V., Carbonell, X. y Oberst, U. (2012). Redes sociales on-line, género y construcción del self. Aloma. Revista de Psicologia, Ciències de l'Educació i de l'Esport, 30 (2), 97-107. https:// www.raco.cat/index.php/Aloma/article/view/263045

Rettberg, J. W. (2009). Freshly generated for you, and Barack Obama: How social media represent your life. European Journal of Communication, 24, 451-466. https://doi.org/10.1177/0267323109345715

Rose, J., Mackey-Kallis, S., Shyles, L., Barry, K., Biagini, D., Hart, C., \& Jack, L. (2012). Face it: The Impact of Gender on Social Media Images. Communication Quarterly, 60 (5), 588-607. https://doi.org/10.1080/01463373.2012.725005

Sádaba, I. y Barranquero, A. (2019). Las redes sociales del ciberfeminismo en España: identidad y repertorios de acción. Athenea Digital, 19 (1). 1-24. https://doi.org/10.5565/rev/athenea.2058 
Arévalo Iglesias, L., y Martínez López de Castro, R.

Instagram como dispositivo de normalización de representaciones identitarias desobedientes. Estudio de caso

Sánchez Duarte, J. M. y Fernández Romero, D. (2017). Subactivismo feminista y repertorios de acción colectiva digitales: prácticas ciberfeministas en Twitter. El profesional de la información 26 (5), 894-902. https://doi.org/10.3145/epi.2017.sep.11

Sánchez-Labella Martín, I., Romo-Parra, C. (2021). Presencia del feminismo institucional en YouTube: estrategia de difusión de la información y ¿movilización de la ciudadanía? Revista de Investigaciones Feministas 12 (1), 79-89.

Sell-Trujillo, L., Núñez Domínguez, T., Aix-Gracia, F. (2021). Flo6x8: intervenciones feministas para la ocupación y la resistencia. Revista de Investigaciones Feministas 12 (1), 145-156.

Táboas-Pais, Ma . I. (2009). Análisis de los estereotipos corporales y de los modelos de actividad. (Tesis doctoral). Universidade de Vigo. Pontevedra. https: / / www.redalyc.org/articulo.oa?id=551656926011

West, C., \& Zimmerman, D. H. (1987). Doing gender. Gender and Society, 1 (2), 125-151. http://links.jstor.org/sici?sici=08912432\%28198706\%291\%3A2\%3C125\%3ADG\%3E2.0.CO\%3B2-W

Wood, J. T. (2009). Gendered lives: Communication, gender and culture. Belmont.

Zafra, R. (2010). Un cuarto propio conectado. (Ciber)espacio y (auto)gestión del yo. Madrid.

\section{AUTOR/ES:}

\section{Lorena Arévalo Iglesias}

Doctora en Comunicación por la UVigo, Máster en Investigación en Comunicación y Licenciada en Publicidad y RRPP. Docente en el grado de Publicidad y RRPP de la Escuela de Comunicación y Ciencias Sociales de CESUGA-Universidad San Jorge e integrante del grupo de investigación en Desarrollo sostenible de la misma universidad. Especialista en semiótica y hermenéutica, su trabajo se enmarca en el ámbito de los Estudios Visuales. Su principal línea de investigación se centra en el análisis de la dimensión dialéctica, poética y retórica de la imagen.

ORCID: https:/ / orcid.org/0000-0002-5136-2138

ResearchGate: https://www.researchgate.net/profile/Lorena_Iglesias4

\section{Rut Martínez López de Castro}

Doctora en Arte y Educación por la UB. Artista, investigadora y docente de educación artística en la Universidad de Vigo. Profesora asociada del Departamento de Didácticas Especiales, Facultad de Ciencias de la Educación y del Deporte. Miembro del Grupo de investigación en Educación, actividad física y salud (GIES10). Su trayectoria profesional transita entre dos ámbitos, el artístico y los procesos educativos. Conforme a esta particularidad su currículo está conformado por creación de obras artísticas, premios 
Arévalo Iglesias, L., y Martínez López de Castro, R.

Instagram como dispositivo de normalización de representaciones identitarias desobedientes. Estudio de caso

artísticos, exposiciones, docencia en el ámbito formal e informal artístico, publicaciones y producción investigadora.

ORCID: https:/ / orcid.org/0000-0002-6005-8998

ResearchGate: https://www.researchgate.net/profile/Rut-Martinez-Lopez-De-Castro 